\title{
Medical English M-Learning: Positioning a New Paradigm in E-Education
}

\author{
http://dx.doi.org/10.3991/ijim.v6i1.1859 \\ Jafar Asgari Arani \\ Kashan University of Medical Sciences, Kashan, Iran
}

\begin{abstract}
This study uses Depth Interview as a research instrument to study users' perceptions and acceptance of the potential use of mobile phones in a prospective design for learning Medical English, a mandatory course in medicine.
\end{abstract}

Almost all the respondents (93\%) across graduates and students were unanimous about the need to learn English through M-Learning. When respondents were asked to suggest ideas on how medical English can be taught through mobiles (unaided question), $49 \%$ suggested SMS and $27 \%$ suggested SMS \& Live Calls.

The survey indicates that there is a unanimous demand to learn English amongst students and graduates of medicine in a new e-education setting called M-learning. Constraints imposed by one's occupation and available resources expose the limitations of traditional learning and opens up a huge opportunity for M-English learning. Irrespective of differences, potential learners accepted the credibility of $\mathrm{M}$ learning and displayed willingness to be an active user of an M-learning module. Diversity of responses on potential frequency of usage for SMSs, preferences regarding listening to IVR, speaking to Live Callers, traditional classroom learning, M-learning and testing options will establish at a primary level that the means of 'engagement', 'presence' and 'flexibility' can be significantly different 'between' and 'within' different educational groups.

Index Terms-M-learning, Students of medicine, Graduates of medicine, Medical English, E-Learning

\section{INTRODUCTION}

Computer-assisted language learning (CALL) is an approach to teaching and learning in which the computer and computer-based resources such as the Internet are used to present, reinforce and assess material to be learned. It usually includes a substantial interactive element. It also includes the search for and the investigation of applications in language teaching and learning.

Except for self-study software, CALL is meant to supplement face-to-face language instruction, not replace it. Computers have recently become fully effective means in various aspects of language teaching. Computer-assisted language learning (CALL) is a method of language teaching and learning in which computer technology is used as an aid to the presentation, storage and assessment of the material which is to be learned. Typical Computerassisted language learning programs present any combination of text, images, sound or video. The user learns the language material by typing at the keyboard, pointing and clicking with the mouse, or speaking into a microphone. Modern Computer-assisted language learning software has embraced CD-ROM and DVD and a wide range of other new technologies, helping in teaching pronunciation, grammar, vocabulary and other aspects of the language.

The current philosophy of CALL puts a strong emphasis on student-centered materials that allow learners to work on their own. Such materials may be structured or unstructured, but they normally embody two important features: interactive learning and individualized learning. CALL is essentially a tool that helps teachers to facilitate the language learning process. It can be used to reinforce what has been already been learned in the classroom or as a remedial tool to help learners who require additional support. The design of CALL materials generally takes into consideration principles of language pedagogy and methodology, which may be derived from different learning theories e.g. behaviorist, cognitive, constructivist and second language learning theories such as Stephen Krashen's monitor hypothesis.

There is no doubt that mobile technologies have started to make their presence felt in the field of education, as can be seen by the increasing number of publications that have appeared in recent years [1] and[7]. The range of research into the use of mobile phones for language learning has been diverse. NGUYEN and PHAM [12] represented a personalized context aware mobile learning architecture for supporting student to learn English as foreign language in order to prepare for TOEFL test. They consider how to apply open learner modeling techniques to adapt contents for different learners based on context, which includes location, amount of time to learn, the manner as well as learner's knowledge in learning progress.

In another study, Kiernan and Aizawa [6] used mobile phones to have learners exchange e-mails with one another in order to teach targeted structures, while Taylor and Gitsaki [11] required their learners to use the browser function of their phones to perform Internet searches, and Levy and Kennedy [8] sent learners language learning related text notifications through SMS about what they had learnt during class or details of upcoming television programs they wanted the learners to watch. Each of these studies capitalizes on different features of mobile phones like e-mail, web browsers and SMS [5] and illustrates the broad potential of the phone as a learning tool. Mobile technology is currently a feasible approach to overcoming many of the obstacles in current methods of EFL (English as a Foreign Language) instruction. Standing on the shoulders of the giant CALL (Computer Assisted Language Learning), mobile assisted language learning (MALL) has the capability of providing EFL learners with the same opportunities for independent and targeted reading practice and immediate corrective feedback as CALL [2]. A paradigm shift has been identified from e-learning 
to m-learning [13]. It is believed that emerging wireless and mobile networks will provide new applications in mobile learning [13].

In Iran where mobile technology is in a rapid growth phase in the semi-urban and rural areas (accounting for the majority of potential English learners), people in general have adopted the wireless technology as a technological tool for their daily need to communicate. However, "widespread acceptance and use of new communication technologies" does not necessarily point to effectiveness or value in the educational context" [8]. The adoption of mobiles as a teaching tool will be a function of "its strengths and limitations both as a technology and as a pedagogical tool, and the social and cultural conditions that surround its use" [8]. Dias (as cited in [8]) opines that while some users might perceive any use of mobiles for education as unwanted intrusion in their private space, other specific groups of users might welcome it. Although many studies have explored new methods of general English language learning made possible by the unique features of MALL, few studies have investigated if mobile technology is acceptable as a complement to teaching more complex structures i.e. English for Medical Purposes (EMP) or medical English. These indicate the need to conduct research on user perceptions about various aspects of a proposed mobile learning module for open user groups. In this study on user perceptions, 'Usability' has been interpreted as the acceptability of the m-learning tool as a reliable, useful, cost effective, and socially compatible platform for learning [9]. The objective was to elicit data that would help in building the basic grounding blocks for an M-learning system where 'learning is an engaging experience' with stress on 'effectiveness and efficiency' [7]. It was also to avoid a situation where potential learners reject 'technologies that are unusable', drop out of courses and find 'alternative education and training providers' [7]. Mobile learning for language learning has reached a stage where it is starting to move out of the classroom and into the real world. Through mobile phones, we have the potential to provide a rich learning environment for our learners, but there are still issues that must be considered before they can reach their full potential. Obviously, there is still the problem of the lack of willingness to try new mobile technologies, but this is something that may slowly become less of an issue as perceptions change [10].

\section{Survey Questions}

This survey was designed to obtain data from two groups of mobile users: the second year students and graduates of medicine. The survey was aimed at collecting data on the following areas for a prospective project design in teaching "English for Medical Purposes" to the students and graduates of medicine:

a) Awareness and perceived credibility and interactivity of learning Medical English through mobile phones.

b) Willingness to learn Medical English through Mobiles

c) Choices and opinions about the following different m-learning options for Medical English: SMS \&SMS + IVR (Interactive Voice Response) for listening and Educational Games.

\section{Project Methodology AND SAMPles}

Depth Interview with a set of pre-designed questions and prod questions was the research instrument and documentation of such interviews was carried out through audio-visual recording without any online editing. The primary pre-survey testing with a sample questionnaire revealed that the subject of M-learning is new for the general population and faulty responses came out of misunderstanding the question. Depth interviews was chosen for its proven ability of exploring new issues and being a better alternative to focus groups while handling individuals who are uncomfortable to speaking in a group.

The survey was conducted with a total sample size of 45 out of which 30 were second year students and 15 were graduates of medicine. The rationale behind choosing these two groups was that these two groups represent the two broad ends of the occupational spectrum ranging from the former having relatively lower degree of mobility to the latter having relatively higher degree of mobility. Also the first group had experienced a short period of $\mathrm{M}$ Learning research by the researcher [2]. However, both had the commonality in terms of a generic 'need to learn medical English'.

\section{SURVEY FINDING: Discussion}

Almost all the respondents $(93 \%)$ across graduates and students (only 3 kept silent) were unanimous about the need to learn English through M-Learning. However, there was a clear difference in the reasons for that need. While the dominant reason for learning English amongst students was 'to progress in life' (40\%) or 'English is used everywhere' $(37 \%)$, none of the graduates expressed the reason as 'progress in life'. For the Graduates medical English was mainly 'good for practice' (47\%). However, the reason that 'English is used everywhere' was a dominant theme for both groups $(42 \%)$ and reflects the overwhelming presence of English in their life. The dominant reason for not trying to learn medical English trough mlearning was 'No Opportunity in University' for both students and graduates.

$57 \%$ of the students were confident that mobiles can serve as a teaching device while only $33 \%$ of the graduates shared that confidence. This probably came from the fact that $37 \%$ of the students had prior familiarity to some kind of m-learning [2] while none from the graduates had such experience. Also amongst the students $73 \%$ were found to be more optimistic about the possibility of Mlearning compared to the graduates $(40 \%)$. However, $100 \%$ of the graduates wanted to try it because of their prior experience or lack of knowledge about M-learning.

When respondents were asked to suggest ideas on how medical English can be taught through mobiles (unaided question), 49\% suggested SMS and 27\% suggested SMS $\&$ Live Calls. $22 \%$ had no idea to offer. One person suggested only live calls. Within the category of SMS (49\%) there were additional ideas of medical Dictionary, special Chatting, Internet Browsers and personal tutors.

When respondents explained the possibility of an English M-Learning module which involved SMS and Live Calls for Reading, Listening and Speaking respectively, $70 \%$ amongst students and $67 \%$ amongst graduates strongly agreed that it would be a better method than just SMS based learning. Though there were no negative responses, the remaining respondents stayed silent which 
generally bordered to agreement or expressed doubts. The doubts were expressed by 2 respondents through statements like 'It would cost us more to listen and to speak' and 'I think just SMS would be enough and we can do without listening or speaking'. When asked to choose between 'Listening on IVR' and 'Speaking to a Live Caller', $20 \%$ opted for Listening and $60 \%$ for Speaking. $18 \%$ felt that neither of them is necessary and only reading through SMS is enough for their learning. An interesting aspect about attitude towards educational methodology amongst the students in our university was revealed when respondents were asked if 'Learning English through educational games in mobiles is possible.' A very strong agreement to the idea was expressed by $47 \%$ of the respondents. Only $13 \%$ were positively inclined to the idea. Notably, $83 \%$ of the negatively inclined group was second year students. $40 \%$ of the respondents stayed silent and doubtful. Those who opposed the idea made statements like 'Games are for children not for adults to learn anything' or 'games are for entertainment and not meant for serious learning'. Those who were optimistic about Educational games expressed ideas like 'learning through games would be interesting and entertaining'.

Across both groups, the most (67\%) preferred volume of SMSs per day is 2-3 SMSs. However, the students preferred a higher number of SMSs than the graduates. The most preferred range for the students was 4-5 or above $(63 \%)$ and for the graduates it was 3-5 (47\%). When asked about the Irritation point for the volume of SMSs, the most common irritation point for $31 \%$ of the respondents was for 7-8 SMS. Preferred time to receive SMSs came in two bands. $43 \%$ preferred after $4 \mathrm{pm}$ and $26 \%$ preferred late evening around 8-9 pm. While the former was mostly the choice for the students the latter was dominated by the choice of the graduates.

$58 \%$ of the respondents who responded to the question on 'how many times in a day they would like to listen to any prerecorded lessons on IVR' gave a range of 1-2 times. $61 \%$ of the respondents who responded to the question on 'how many times they would speak if given the option of speaking to a live caller' indicated a range of 1-2 times.

$80 \%$ of the respondents said that they would like to take tests over mobile and 9\% went against it. $11 \%$ stayed silent. $50 \%$ preferred to take tests 'once in 7 days', $36 \%$ 'once in 15 days' and $14 \%$ 'once in 30 days'. There was however a perceptible difference between students and graduates as only $67 \%$ of graduates liked the idea of taking tests as against $87 \%$ amongst students. $20 \%$ chose to remain silent on this question.

$33 \%$ said that Mobile learning would work better for them if they wanted to learn English and they won't miss the classrooms. $47 \%$ preferred the classroom training if constraints of time and availability of resources were not there. Responses from individuals who preferred $\mathrm{M}$ learning had 'Anytime anywhere learning' as a recurrent theme along with 'no fear of being ridiculed', 'we are quite responsible' and 'I would concentrate better'.

\section{CONCLUSION}

According to the questionnaire survey, the learners appreciate convenience, connectivity, portability, immediacy and push aspect, which are the attributes of m-technology .The survey indicates that there is a unanimous demand for learning English amongst 'students and graduates of medicine. However, constraints imposed by one's occupation and available resources expose the limitations of traditional learning and opens up a huge opportunity for Mlearning. Irrespective of differences, potential learners accepted the credibility of M-learning and displayed willingness to be an active user of an M-learning module. Issues about learner's 'engagement', 'presence' and 'flexibility' which have been proven as effective criteria for evaluating mobile learning environments [3] have been partially addressed. Owing to the limited time, technical support, number of subjects involved and the narrow focus of the M-learning project, the results have to be interpreted with caution. It should also be emphasized that interactivity was not fully achieved in the learning because of the limitations of SMS technology. Responses from those who preferred classroom learning made statements like 'Classroom learning is better as the teacher always tells us what to do and will help us if we are stuck somewhere. But in mobile learning the instructor would send a SMS and if we are unable to understand something then it is up to us to call and find out' or 'reading alone will be boring'. In addition, M-learning is not going to replace face-to-face learning; it is applied in a blended model.

Now that our M-learning project learners appreciate the presence and attributes of such a paradigm in the university system, it is necessary to be ready to meet their needs. The university should consider new facilities, equipments and human resources in a wireless and mobile network.

Our ongoing research would strive to validate the above findings with a larger and more representative sample across the university. Further research also needs to be done with other educational groups. Responses on attitudes towards educational games create the scope for exploring the prima facie reluctance of Iran adult learners towards accepting educational games as a valid educational tool. The intricacies of designing such games have been earlier displayed by the primary research on designing learning games for children [4].

\section{REFERENCES}

[1] Ally, M. (Ed.). Mobile learning: Transforming the delivery of education \& training. Athabasca: AU Press. 2009.

[2] Asgari Arani, J. Mobile English Learning in a Face to Face Situation: A Blended Model, Modern English Teacher Magazine, London, Jan. 2010.

[3] Danaher.P, Gururajan.R, \& Hafeez-Baig. A. Transforming the Practice of Mobile Learning: Promoting Pedagogical Innovation through Educational Principles and Strategies that Work. In H.Ryu \& D.Parsons (Ed.), Innovative Mobile Learning: Techniques and Technologies (pp 21-46).Hershey: IGI Global.Internet \& Mobile Association.45 million Internet users [Data File] 2009. Retrieved from http://www.iamai.in/PresRelease.aspx?NYear=2009\&Nmon $\underline{\mathrm{th}=1}$.

[4] Kam, M., Agarwal, A., Kumar, A., Lal,S., Mathur, A., Tewari, A., et al.Designing E-Learning Games for Rural Children: a Format for Balancing Learning with Fun. 2008 Accessed at: http://www.cs.berkeley.edu/ jfc/papers/08/DIS2008.pdf

[5] Kennedy, C., \& Levy, M. L'italiano al telefonino: Using SMS to support beginners' language learning. ReCALL, 20(3), 315-350. Routledge2008.

[6] Kiernan, P., \& Aizawa, K. Cell phones in task based learning. Are cell phones useful language learning tools? ReCALL, 16(1), 7184. 2004. http://dx.doi.org/10.1017/S0958344004000618

[7] Kukluska-Hulme, A.. Mobile Usability \& user experience. In A. Kukluska-Hulme \& J.Traxler (Ed.), Mobile Learning: A handbook of educators and trainers (pp. 45-56). Oxon: Routledge. 2005 


\section{SHORT PAPER}

\section{Medical English M-LeARning: Positioning A NeW PARAdigm In E-EduCATION}

[8] Levy, M. \& Kennedy, C. Learning Italian via mobile SMS. In A.Kukluska-Hulme \& J.Traxler (Ed.), Mobile Learning: A handbook of educators and trainers (pp. 76-83). 2005.

[9] Oxon:Routledge. Nielsen, J. Usability Engineering. Boston, MA: Academic Press. 1993.

[10] Stockwell, G.. Investigating learner preparedness for and usage patterns of mobile learning. ReCALL, 20(3), 253-270. 2008 http://dx.doi.org/10.1017/S0958344008000232

[11] Taylor, R.P., \& Gitsaki, C. Teaching WELL in a computerless classroom. Computer Assisted Language Learning, 16(4), 275294. 2003. http://dx.doi.org/10.1076/call.16.4.275.23412

[12] Viet Anh NGUYEN and Van Cong PHAM. Learner Open Modeling in Adaptive Mobile Learning System for Supporting Student to Learn English . iJIM - Volume 5, Issue 4, October . 2011. http://dx.doi.org/10.3991/ijim.v5i4.1789

[13] Upadhyay, N .M-Learning - A New Paradigm in Education. International Journal of Instructional Technology and Distance Learning. 3(2), pp. 31-34.2006

\section{AUTHOR}

Jafar Asgari Arani is a full time faculty member of Kashan University of Medical Sciences, English Department. (email: Askari@kaums.ac.ir)

Received 2 November 2011. Published as resubmitted by the author 14 December 2011. 